\title{
Artelogie
}

Recherche sur les arts, le patrimoine et la littérature de l'Amérique latine

\section{Las relaciones al pasado en la fotografía latinoamericana: por un acercamiento estético y antropológico de la fotografía}

\section{Mathieu Corp}

\section{(2) OpenEdition}

Edición electrónica

URL: https://journals.openedition.org/artelogie/1151

DOI: 10.4000/artelogie.1151

ISSN: 2115-6395

Editor

Association ESCAL

Referencia electrónica

Mathieu Corp, «Las relaciones al pasado en la fotografía latinoamericana: por un acercamiento estético y antropológico de la fotografía», Artelogie [En línea], 7 | 2015, Publicado el 15 abril 2015, consultado el 11 abril 2022. URL: http://journals.openedition.org/artelogie/1151 ; DOI: https://doi.org/ 10.4000/artelogie. 1151

Este documento fue generado automáticamente el 11 abril 2022.

Association ESCAL 


\title{
Las relaciones al pasado en la fotografía latinoamericana: por un acercamiento estético y antropológico de la fotografía
}

\author{
Mathieu Corp
}

La penetración dialéctica en contextos pasados y la capacidad dialéctica para hacerlos presentes es

la prueba de la verdad de toda acción contemporánea. Lo cual significa : ella detona el material explosivo que yace en lo que ha sido [...] Acercarse así a lo que ha sido no significa, como hasta ahora, tratarlo de modo histórico, sino de modo político.

Walter Benjamin, Libro de los pasajes

\section{Fotografía latinoamericana: una categoría por defecto, una escala a pesar de todo}

1 La existencia de una categoría "fotografía latinoamericana" es tan criticable como la noción de identidad latinoamericana es criticada, en cuanto la primera designa un conjunto coherente de practicas fotográficas y que la segunda remite a un conjunto de atributos estables, homogeneizante y comúnmente compartidos al seno del vasto espacio geográfico que designa América latina. Esta apelación es sin embargo corrientemente empleada en numerosas manifestaciones artísticas desde hacen ya varias décadas.

2 Se considera generalmente que el evento que preside a la creación oficial de esta categoría es el Primer Coloquio Latinoamericano de Fotografía organizado en 1978 a México. Explicar la existencia de una categoría "fotografía latinoamericana" (y no 
caracterizar sus producciones) requiere un importante análisis histórico con desarrollo, que el formato de ese articulo no permite. Sin embargo, tres factores pueden ser identificados para explicar su emergencia : la posición periférica de América latina respecto al mercado del arte occidental que necesita federar los esfuerzos para pretender de manera mas eficaz a un reconocimiento (pero también porque a ese mercado le gusta categorizar en términos de alteridad las producciones que identifica como ajena a Occidente) ; la relativa comunidad sociocultural que forman los países de América latina que brota de una experiencia histórica similar y que alimenta esa posición periférica; $y$, por ultimo, los precedentes artísticos latinoamericanos de la primera mitad del siglo XX caracterizados por una búsqueda de "lo propio" y entonces por una voluntad de identificar especificidades nacionales y/o latinoamericanas. Todos esos factores son interdependientes y ninguno podría por él solo explicar la existencia de la categoría fotografía latinoamericana. El propósito de ese artículo no es de sostener o no la validez de tal categoría, sino analizar algunos de los predicados sobre los cuales reposa desde los años 1990.

3 En el texto de introducción del catalogo de la exposición que acompaña el Primer Coloquio Latinoamericano de Fotografía, la critica mexicana de arte Raquel Tibol declaraba que "lo que tienen en común los fotógrafos latinoamericanos" es el "desprecio por las descripciones superficiales que nos aspiran a revelar las relaciones entre el hombre y su espacio social y natural". La idea que quiere que los fotógrafos latinoamericanos estarían esencialmente animados por el deseo de representar el contexto en el cual trabajan, ha sido ampliamente criticada desde los años 1990. Al focalizar la mirada sobre la cualidad documental de las imágenes, esa idea obstaculiza el reconocimiento de la cualidad artística de las obras y la posibilidad por los artistas de hacer avanzar los debates teóricos y plásticos del campo del arte . La virulencia de las criticas dirigidas contra la obra de la historiadora Erika Billeter (publicado en 1993), en el cual negaba a los fotógrafos latinoamericanos la capacidad de experimentación artística, es un síntoma del trastorno que sucede en los años 1990 en la manera de pensar y de caracterizar la fotografía latinoamericana.

4 A partir de los años 1990, críticos y curadores pretenden observar una ruptura en las representaciones fotográficas de América latina. Por números curadores, uno de los síntomas de esa evolución sería el numero decreciente de trabajos documentales de tipo reportajes en las muestras de fotografía latinoamericana. No hay que olvidar sin embargo que esta constatación se explica tanto por una política curatorial, como por los trastornos del estatus de documento de la imagen fotográfica que ha significativamente contribuido a que evolucionan las practicas fotográficas artísticas . Lo que cambió radicalmente a partir de los años 1990, es la manera con la cual la categoría fotografía latinoamericana está concebida. En adelante, curadores y críticos niegan la existencia de tal categoría como conjunto coherente y homogéneo de practicas y representaciones. Al contrario argumentan a favor de un reconocimiento de la heterogeneidad de las practicas fotográficas y de los contextos a los cuales remite la escala "América latina". Si no se quiere reconocer especificidades a la fotografía latinoamericana, como justificar entonces la escala América latina de las muestras que están organizadas?

5 Esta escala es justificada por los curadores en virtud de la identificación de temáticas y de preocupaciones que serían recurrentes en las proposiciones fotográficas a partir de los años 1990. En las grandes exposiciones de fotografía latinoamericana se encuentra 
efectivamente muy a menudo las mismas categorías temáticas con simplemente algunas variaciones en el vocabulario pero siempre con los mismos campos semánticos movilizados. Por consiguiente, aunque sea en adelante comúnmente admitido que la categoría fotografía latinoamericana no designa un conjunto de practicas homogéneas, la existencia de esta categoría es sostenida por las muestras y los eventos que retoman esta apelación (bienales, foros, festivales) y sobre todo por las categorías temáticas que emplean, que organizan y delimitan el campo cubierto por la apelación fotografía latinoamericana. Ahora bien, entre esas categorías temáticas (así como en la mayoría de los textos críticos acerca de la fotografía latinoamericana), los términos que están utilizados con mas frecuencia son: historia, memoria e identidad. ¿Siguen esos términos motivando un acercamiento contextual de la fotografía latinoamericana?

\section{Historia, memoria e identidad, propósitos recurrentes de la fotografía latinoamericana}

6 Mas allá de las categorías temáticas, los términos historia, memoria e identidad están empleados de manera recurrente por críticos y curadores para cualificar los propósitos de numerosos trabajos fotográficos contemporáneos. En esos escritos, muy a menudo la pareja memoria e identidad sirve por justificar la idea que los artistas pluralizan las relaciones a la historia. Por Juan Antonio Molina, critico y curador : "Cualquier análisis suficientemente desprejuiciado de la fotografía contemporánea latinoamericana demostraría que mediante la fotografía no realista se están abriendo puertas alternativas para una nueva relación entre los sujetos y la historia [...] estas relaciones alternativas con la historia se dan básicamente mediante la construcción de historias alternativas". Esas historias alternativas no sabrían sin embargo substituirse a las historias oficiales ya que no comparten siempre su escala, que por otra parte, la enunciación que las mediatiza no goza de la autoridad del historiador o de la del Estado (autoridad que, a pesar de la desconfianza, no ha sido transferida hacia otra instancia enunciativa), en fin y sobre todo, porque al asumir su estatus fragmentario, solo pueden intentar describir un segmento de realidad histórica, como un detalle al seno de un cuadro. Es por eso que, preferimos hablar de pluralización de las relaciones al pasado que de historias alternativas.

7 Por numerosos críticos y curadores, esas historias alternativas caracterizan un reposicionamiento critico de numerosos fotógrafos con respecto a las representaciones precedentes de América latina: "Durante los años 1990, los fotógrafos intentan deshacerse de la imagen rural, violenta y tercermundista común en las representaciones de la década anterior, es decir de sobrepasar el culto del realismo mágico y del indigenismo". Comprometerse con una búsqueda memorial e identitaria seria el modo mediante el cual los artistas deconstruyen, y reconstruyen a veces, esas representaciones. La utilización del termino memoria se explica por la importancia y la credibilidad adquirida por la memoria como herramienta de los saberes históricos desde el replanteamiento de los métodos y presupuestos historiográficos durante la segunda mitad del siglo XX , pero también por la posición de enunciación de los artistas y por el hecho de que se interesan a un fragmento de la realidad histórica y no a la historia como relato lineal y global. Esas relaciones al pasado, dadas mediante la memoria, no aferran la fotografía latinoamericana en un "paseismo" nostálgico o un resentimiento anacrónico, pues es "en función del presente" que "relecturas constantes 
del pasado, que debe poder ser constantemente cuestionadas", están realizadas . Además, el carácter esencialmente vivo y dinámico de la memoria manifiesta la contemporaneidad de las problemáticas que motivan esas relaciones al pasado.

El pasado al cual los artistas hacen referencia es tremendamente diverso, puede concernir el periodo prehispánico, el periodo colonial, las guerras que siguieron las independencias y las dictaduras (donde se destaca el tema de la memoria de los desaparecidos). Sin embargo, en el conjunto de las imágenes, esas relaciones al pasado conducidas desde el presente se traducen muy a menudo por la cohabitación de referencias provenientes de temporalidades heterogéneas (pasadas o presentes). Con puestas en escena, yuxtaposición de imágenes y manipulación de archivos, los artistas producen anacronismos significantes. El anacronismo es una modalidad recurrente para realizar este reposicionamiento, aunque no determina su valor critico. En la tesis de la cual resultan las reflexiones que componen este articulo, distinguimos las diferentes problemáticas que motivan esos anacronismos y analizamos la articulación de las categorías pasado/presente que instauran, es decir, la manera con la cual las imágenes contribuyen a modificar la representación del pasado y del presente. A partir del análisis de dos trabajos contemporáneos y a título de ejemplo vamos a presentar dos de las principales relaciones al pasado que se pueden distinguir en muchos trabajos fotográficos de América latina. Con el fin de sostener la relevancia de esas relaciones haremos referencia a otros trabajos fotográficos contemporáneos en los cuales se pueden identificar, aunque tratando de no corromper la singularidad de cada uno de esos trabajos.

\section{Reapropiarse el pasado, relectura de la historia colonial}

9 En el 2011, la artista guatemalteca Verónica Riedel produce une serie de retratos con el fin de rehabilitar el lugar de las mujeres en la formación de las sociedades mestizas latinoamericanas. Como lo hace otro artista guatemalteca, Luis González Palma, en una serie titulada Guardaespaldas (2009), Verónica Riedel revisita la iconografía colonial y en particular los retratos de dignitarios - por cierto encontramos la lechuguilla o cuello blanco de encaje que llevaban en la época los aristócratas - sin embargo subvierte esta iconografía utilizando modelos femeninos provenientes de las comunidades indígenas del país e integrando toda una gama de otros elementos que forman una trama compleja e híbrida de referencia. Numerosos documentos históricos son utilizados, como mapas, ilustraciones, extractos de obras, todos al parecer producidos durante el periodo colonial. A esos documentos se adjuntan otros tipos de elementos cuya materialidad remite explícitamente a una enunciación indígena : extractos de códices, glifos mesoamericanos, pero también abundante y ricos ornamentos quienes, incrustados sobre las fotografías, hacen referencia al barroco colonial tanto como a los artes precolombinos (Figura 1). Con esta serie de retratos, la artista pretende sobrepasar el papel de victima atribuido a las mujeres en la constitución de las sociedades latinoamericanas. Victima o traidora, con la Conquista el papel de las mujeres indígenas en la génesis de las identidades en América latina es siempre percibido en términos negativos. Con la serie Mestiza, Reinas de Américas, Verónica Riedel quiere revertir esa lectura para presentar esas mujeres ya no solo como victimas de las circunstancias de la Conquista, sino como "Reinas" capaces de figurar con honor 
y dignidad la Maternidad de las sociedades latinoamericanas. Por lo tanto, esa inversión no hace abstracción de la violencia de la Conquista, encontremos por ejemplo a modo de segundo plano de los retratos, documentos utilizados durante el periodo colonial para llevar a cabo la evangelización de los indígenas o la primera pagina de la famosa obra del dominico Bartolomé de la Casas quien fue une de los primeros europeos a condenar el trato infligido a los Indios (Figura 2). Si esos distintos elementos remiten a la violencia de la Conquista, es primero la actitud y la mirada digna de esas mujeres que interpela el espectador en esos retratos.

10 Verónica Riedel elabora una representación de las mujeres que rehabilita su papel en la construcción de las sociedades coloniales y que coloca el mestizaje al centro de ellas aunque organizando la composición de los retratos respecto a una matriz colonial que constituye aquí los retratos de dignitarios. La artista conserva entonces una parte del relato histórico que quiere que la cultura ibérica se impone a las culturas autóctonas. Sin embargo, la integridad de esta lectura está alterada por las intervenciones que realiza sobre la imagen. Esas intervenciones contribuyen a demostrar que el universo conceptual ibérico y sus referencias no se imponen termino a termino a las culturas autóctonas. La imposición de ese marco referencial se realiza mediante una negociación que, aunque desequilibrada, modifica los marcos referencias de sus diferentes actores para construir uno nuevo, hibrido. Verónica Riedel propone una forma de relectura de la historia a partir de una reapropiación y una hibridación de distintos repertorios iconográficos (prehispánico y colonial).

Otros trabajos fotográficos han contribuido a rehabilitar el lugar de los componentes prehispánicos e Indigenas (contemporáneos) en las sociedades latinoamericanas dentro de los cuales los de Tatiana Parcero, de Adriana Calatayud, de Ambra Polidori o de Luis González Palma. Esos trabajos no están sistemáticamente habitados por una nostalgia del pasado prehispánico. En efecto, se interesan menos al valor mítico del patrimonio prehispánico que a evidenciar los sincretismos y la hibridación cultural cuya identidad contemporánea es a la vez el fruto y el indice del dinamismo que los caracteriza. Es por eso que el pasado prehispánico no es el único referente de ese tipo de trabajos. En las fotografías de Mario Cravo Neto, Marta María Pérez Bravo, Eustáquio Nevez o Víctor Vázquez, el interés por el sincretismo y las formas de hibridación se vincula con otros componentes culturales de las sociedades latinoamericanas. En otros trabajos, como los de Gerardo Suter en México, de Mario Silva Corvetto y Javier Silva en Perú, el pasado prehispánico está concebido en términos de mitología identitaria. Sin embargo, esos trabajos no hacen la amalgama que hizo muy a menudo el indigenismo al considerar las comunidades indígenas como testimonios vivos y atemporales del pasado prehispánico. Por ejemplo, si Pablo López Luz o Susana Torres se interesan a las formas supervivientes del pasado prehispánico en el contexto contemporáneo (con el sentido que Aby Warburg da de "formas supervivientes"), Maruch Sántiz Gómez evidencia en cuanto a ella el carácter vivo de las culturas indígenas contemporáneas.

\section{La memoria contra la historia nacional y la deconstrucción de sus mitologías}

12 La memoria juega un papel mucho más explícito en los trabajos que se refieren a un pasado más reciente en la medida que se vuelve el instrumento de una alternativa a la historia oficial. A modo de ejemplo, la artista brasileña Rosângela Rennó presentó en 
1994 en el marco de una muestra nombrada Revendo Brasília una instalación de fotografías titulada Imemorial. Las imágenes expuestas provienen de una selección en un conjunto de archivos (que nunca habían sido expuestas) abarcando 15000 fotografías de obreros de la compañía gubernamental brasileña que participó a la construcción de la nueva capital, Brasilia, inaugurada el 21 de abril de 1960. El proyecto suscitó en la época el interés de numerosos fotógrafos que encontraron en las líneas geométricas y los volúmenes de los edificios ocasiones de reconducir el éxito de la fotografía modernista. En esas fotografías (las de Marcel Gautherot en particular quien fotografió la ciudad durante su construcción), la dimensión humana de la empresa es casi sistemáticamente ocultada en beneficio de su valor arquitectónico (Figura 3 y 4). El fotógrafo francés Lucien Clergue consagra él también la misma atención preeminente a la audacia arquitectural durante una estancia que realiza en la capital algunos años después de su inauguración. Sin embargo, ciertas imágenes presentan un inquietante contraste con esa representación modernista: fotografías del cementerio de Brasilia (Figura 5). Cavadas en la tierra sin ninguna lápida mortuoria, el cementerio y sus tumbas al parecer no han hecho parte de los planos de ordenamiento urbano, como si la ciudad se concebía exclusivamente dirigida hacia el porvenir.

En los archivos a partir de los cuales Rosângela Rennó concibió la instalación Imemorial, numerosas fotografías de los obreros que participaron a la construcción de la ciudad han sido reagrupadas bajo la mención "dispensado por motivo de muerte". Al termino de la construcción, cerca de 40000 obreros vivían en el sitio, todos inmigrados de la región del Nordeste, trabajando catorce horas por día. En febrero de 1959, ciertos de ellos iniciaron una huelga que fue reprimida en la sangre. Los cuerpos fueron enterrados en un lugar conservado secreto y por falta de cuerpos de delito, ninguna acción jurídica ha sido comenzada por el momento. Un grupo de investigadores de la Universidad de Brasilia trabaja actualmente a la "reconstrucción de la memoria de este hecho histórico que fue ocultado de la historia oficial de Brasil" . El termino memoria manifiesta aquí implícitamente una oposición con el termino historia y infiere un uso de éste que responde a la concepción tradicional según la cual el Estado posee el monopolio de la historia. La noción de memoria está inscrita en una concepción política y la puesta al día de ese evento respondería entonces a un deber de memoria. La exigencia de un "deber de memoria" responde a un compromiso ético, entendido como "exigencia de una lucha contra el olvido que la historia no sabría satisfacer" .

El termino historia empleado en esta cita, o la "historia oficial" de la cita anterior, designa lo que Nietzsche llama la "historia monumental" en la obra titulada Consideraciones intempestivas. Se trata de una historia que, por voluntad de cohesión y de grandeza, hace "violencia a la realidad individual del pasado" y a menudo no es mas que une "ficción mítica" . En una obra titulada, Brasilia : o mito na trajetória da Nação, el sociólogo brasileño Márcio de Oliveira muestra cuanto la construcción de la nueva capital sirvió para fundar un mito moderno de la nación brasileña. El titulo de la instalación de Rosângela Rennó Imemorial, denota el hecho que es esta historia que ataca, siendo el memorial un de los medios tradicionales de la historia oficial. El prefijo "im", utilizado aquí como privativo, tiene en cuenta el estatus clandestino de la memoria que está expuesta. La disposición de las fotografías en el espacio de la muestra, así como los materiales utilizados, hacen sin embargo explícitamente referencia a los monumentos funerarios, lugares tradicionales de la historia oficial (Figura 6). Los retratos de los obreros han sido ampliados y alterados por incisiones 
practicadas sobre la imagen y por lesiones producidas por la oxidación de los pernos que la cuelgan. Sin embargo, las lesiones no son ubicadas en particular en el cuerpo de los obreros, es la imagen que sangran (Figura 7 y 8). Entonces el procedimiento utilizado no pretende tanto ejemplificar la violencia que sufrieron los obreros sino la que está hecha a esta memoria cuyas imágenes constituyen los testimonios.

Rosângela Rennó da a esos archivos la posibilidad de una existencia mediática en el espacio publico de la muestra. Pero, el propósito de esta instalación no sabría ser reducido a la nueva visibilidad que la artista da a las imágenes. Los recursos estéticos que emplea tienen una función metafórica y metonímica que sobrepasa ese propósito. Sirven para expresar la manera con la cual la existencia publica de las imágenes es sometida a relaciones de poder y voluntad de control : al mantener esas imágenes en el olvido, se trataba de proteger la representación canónica de la ciudad de Brasilia. Restituyendo una parte trágica del relato de la construcción de la ciudad, su historia (el pasado) se modifica y su representación, sustentada por una ficción mítica, es quebrantada (en el presente).

Numerosos otros trabajos contemporáneos se aplican a deconstruir esas ficciones míticas que alimentan las identidades nacionales - el artista venezolano Alexander Apóstol con la serie Ensayando la postura nacional o el peruano Fernando Gutiérrez en una serie consagrada al "Huáscar" - y disimulan eventos particularmente violentos de la historia de los países concernidos - el artista argentino res con la serie NECAH/1879. Muy a menudo, esos trabajos no se conforman solamente con deconstruir esas ficciones sino que se sirven de ellas para echar una mirada critica sobre el contexto contemporáneo - pensamos por ejemplo a las fotografías del argentino Leonel Luna.

\section{Por un acercamiento estético y antropológico de la fotografía}

La mayoría de los curadores y críticos que se interesan a la fotografía latinoamericana se aplican a describir las implicaciones contextuales de los distintos trabajos. Es cierto que el valor critico de esas fotografías no puede ser correctamente evidenciado sin un esfuerzo de contextualización. Ese esfuerzo es sin duda una consecuencia de la amplitud de la escala geográfica que cubre la categoría fotografía latinoamericana. Sin embargo, es claro que ese esfuerzo de contextualización no basta ya que el valor critico de esos trabajos depende también de los recursos formales empleados por los artistas, es decir, de su valor artístico. Para cada uno de sus trabajos, los artistas desarrollan recursos formales que se distinguen por su creatividad tanto como por los vínculos que tejen con diferentes tipos de imágenes y medios (pintura, video, instalación, escultura, etc.). Al apropiarse de numerosos usos y practicas de la historia de la fotografía (artísticos como vernáculos), esos trabajos toman plenamente parte a los debates teóricos que hacen evolucionar el estatus y el valor de la imagen fotográfica y pluralizan sus usos. La virtuosidad técnica del artista colombiano Oscar Muñoz y el valor experimental de sus producciones determinan la gran calidad de la reflexión que fomentan respecto a la vida mediática de las imágenes y a la capacidad de recordar los eventos que representan. Esa reflexión posee un valor que sobrepasa el aferramiento contextual colombiano, aunque esté vinculada con problemáticas particularmente sensibles respecto al conflicto interno que sacude Colombia desde hace mas de medio siglo. 
El valor critico que poseen las imágenes respecto al contexto de enunciación y/o de referencia de los artistas es entonces necesariamente vinculado a la calidad artística de los trabajos fotográficos. Es por eso que pensamos que solo un análisis a la vez estético y antropológico de las fotografías es capaz de sacar a la luz la relación de dependencia mutual entre esos dos valores.

\section{Ilustraciones}

Figura 1, "Suchil", de la serie Mestiza, Reinas de América, 2011

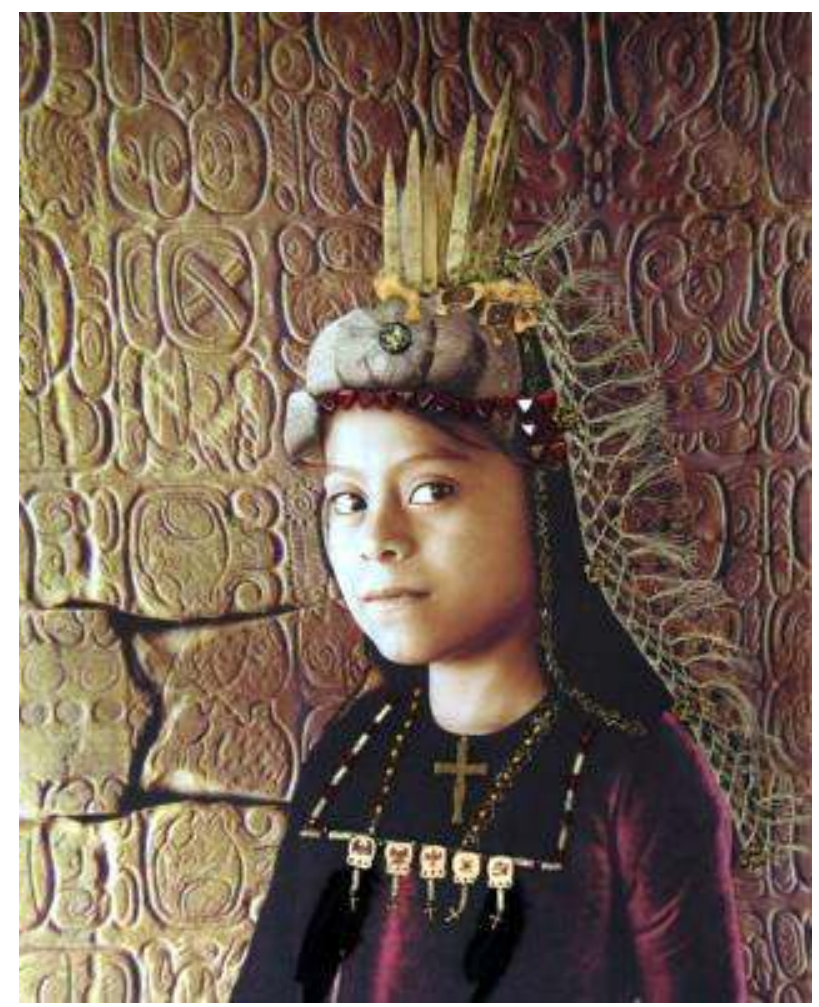

(c) by Veronica Riedel 
Figura 2, "Baki", de la serie Mestiza, Reinas de América, 2011

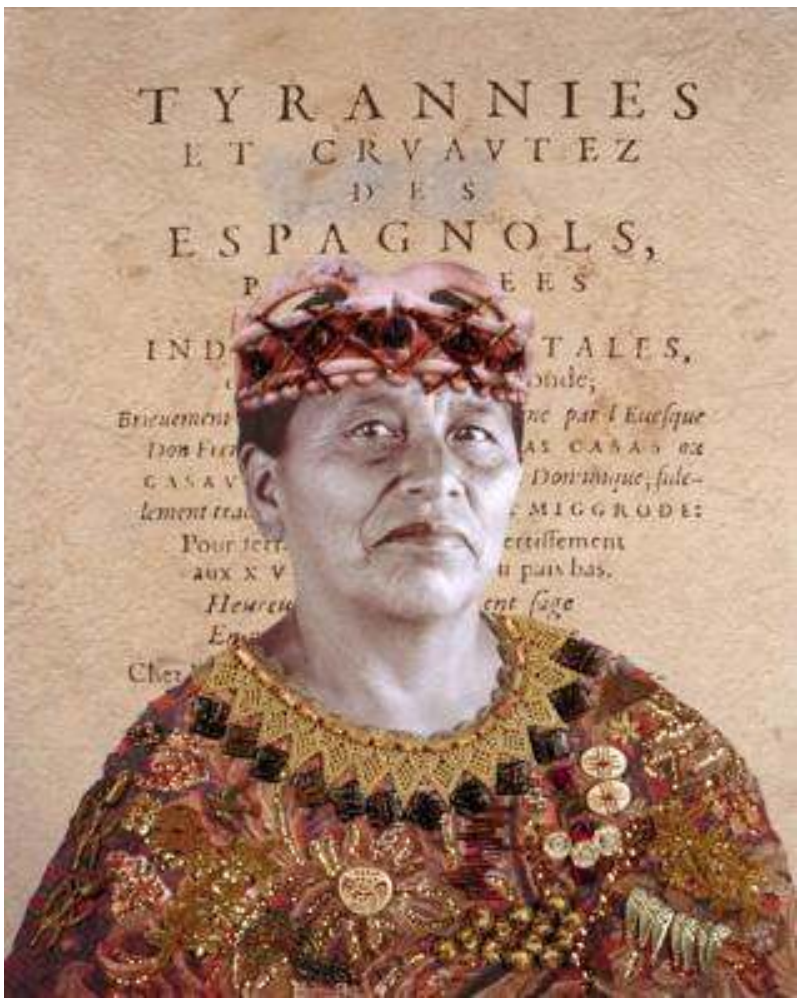

(c) by Veronica Riedel

Figura 3, Marcel Gautherot, sin titulo, Brasilia, 1958

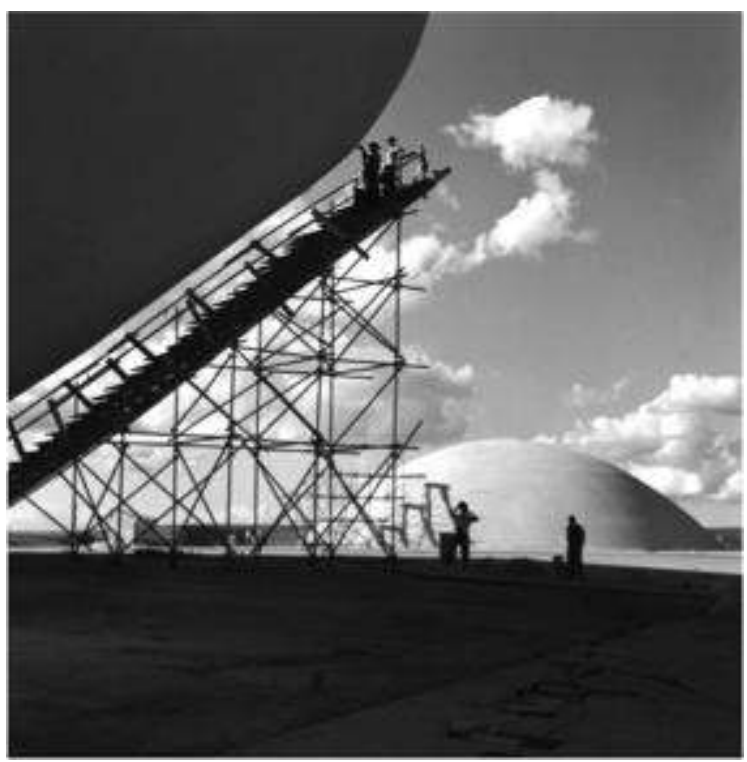


Figura 4, Marcel Gautherot, sin titulo, Brasilia, 1958

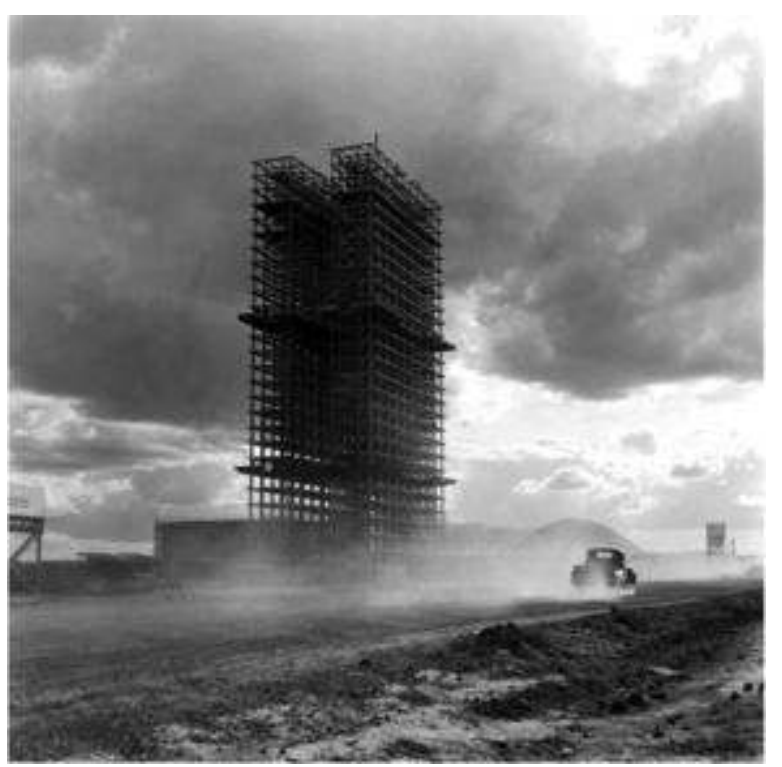

Figura 5, Brasília, p. 163, 1963

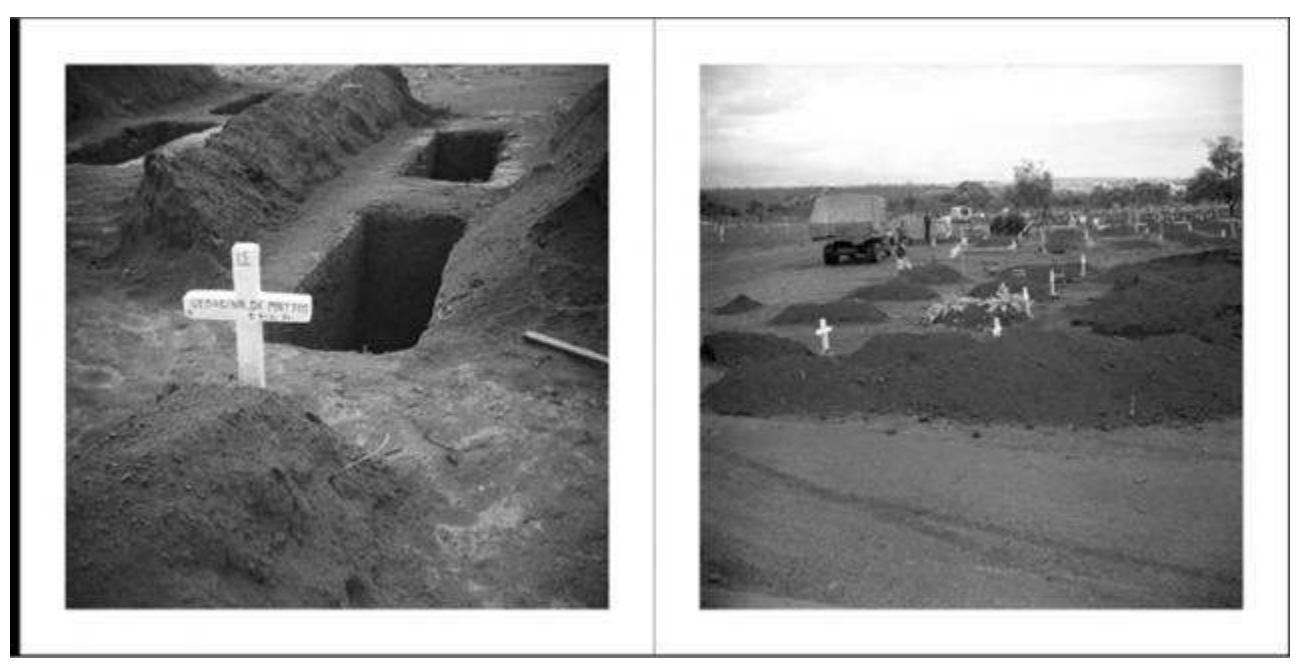

(c) by Lucien Clergue 
Figura 6, Rosângela Rennó, vista de la exposición “Imemorial”, 1994

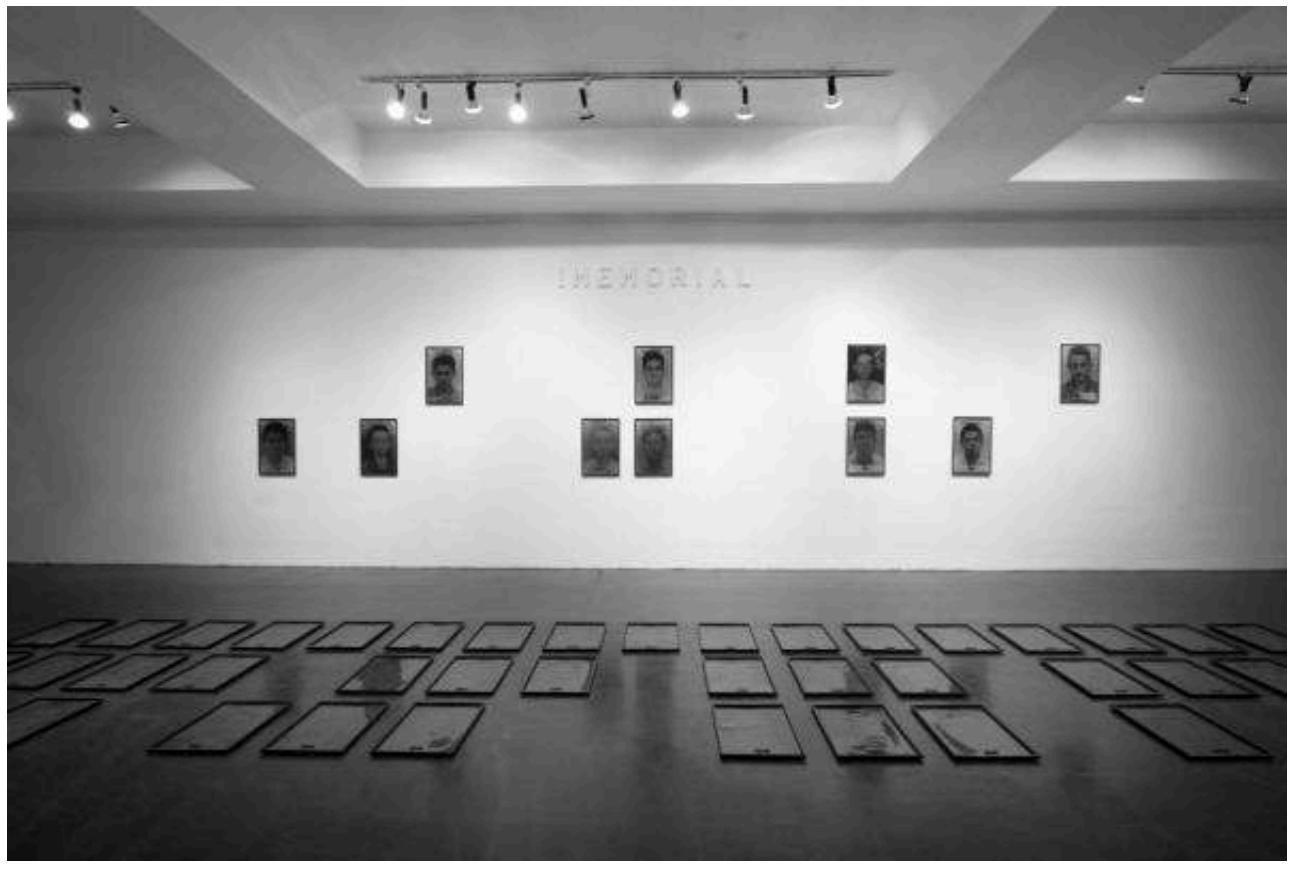

(c) by Flavio Lamenha

Figura 7, Rosângela Rennó, Imemorial, 1994

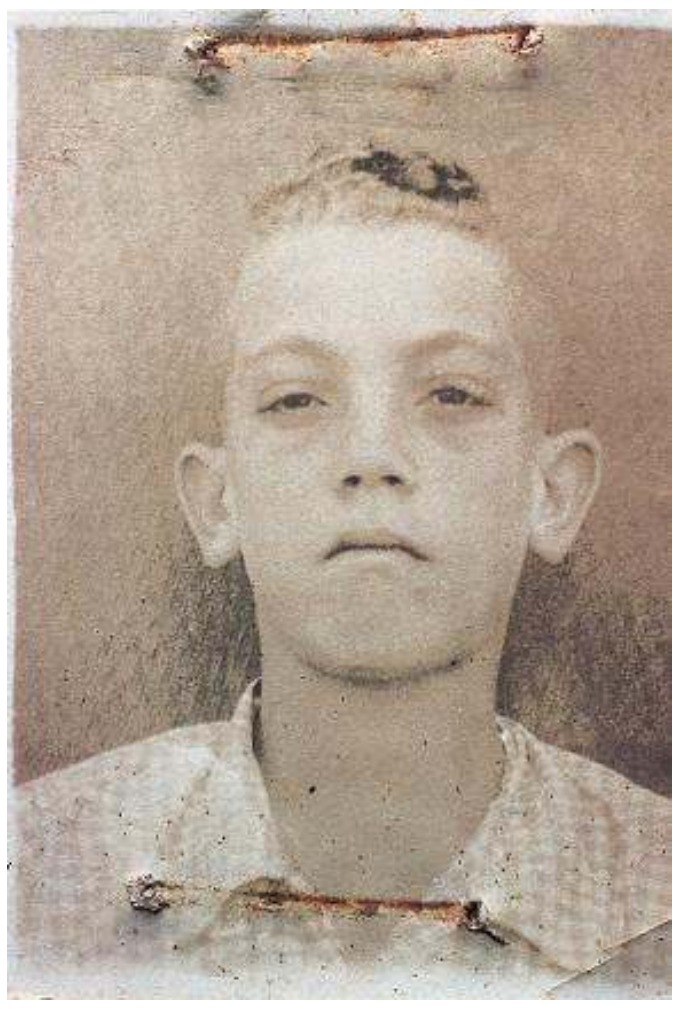

(c) Arquivo Público do Distrito Federal 
Figura 8, Rosângela Rennó, vista de la instalación Imemorial, 1994.

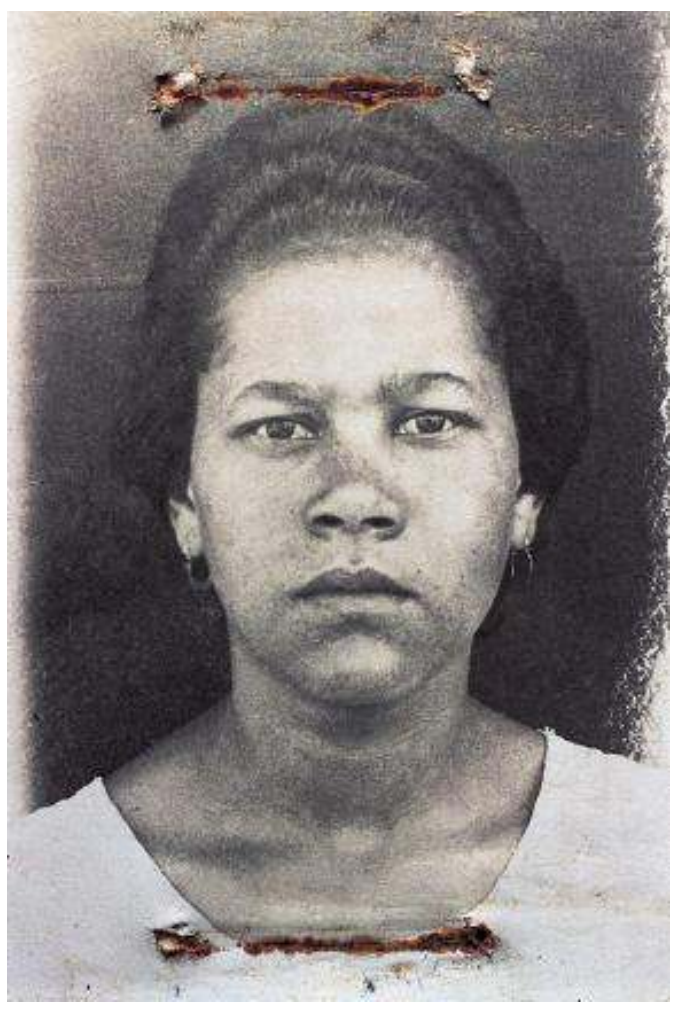

(C) Arquivo Público do Distrito Federal

\section{BIBLIOGRAFÍA}

Image and Memory, Houston, University of Texas, 1998.

Mapas Abiertos, fotografía latino-americana, 1991-2002, México, Lunwerg, 2003 : "Rituales de identidad", "Escenarios" y "Historias alternativas".

Los marcos sociales de la memoria, Barcelona, Anthropos, 2004.

La memoria colectiva, Prensas Universitarias de Zaragoza, 2004.

PAz Octavio, El laberinto de la soledad, México, Fondo de Cultura Económica, 1959.

LAVABRE Marie-Claire, « Usages et mésusages de la notion de mémoire », Critique internationale, $\mathrm{n}^{\circ} 7$, Paris, Les Presses de Sciences Po, avril 2000, p. 51.

\section{NOTAS}

1. Por el sociólogo peruano Aníbal Quijano: «La identidad latinoamericana, que no puede ser definida en términos ontológicos, es una compleja historia de producción de nuevos sentidos 
históricos, que parten de legítimas y múltiples herencias de racionalidad ». Aníbal Quijano, Modernidad, Identidad y utopía en América Latina, Quito, El Conejo, 1990., p. 69.

2. Al respecto referirse en particular a Ivonne Pini, En busca de lo propio. Inicios de la modernidad en el arte de Cuba, Mexico, Uruguay y Colombia, Bogotá, Universidad Nacional de Colombia, 2000.

3. "Desde el siglo XIX han existido propuestas para definir lo latinoamericano, concebidas como tareas ontológicas y políticas. Se buscaba el ser nacional o de la región: la brasileñidad, la mexicanidad, la peruanidad, y como síntesis el "ser latinoamericano". A veces, idealizando las raíces indígenas, en otros casos potenciando la unidad de "carácter" que nos habría dado la modelación ibérica”.Nestor Garcia Canclini, Latinoamericanos buscando lugar en este siglo, Buenos Aires, Paidós, 2002, p. 35.

4. Raquel Tibol, Hecho en Latinoamérica, Primera muestra de la Fotografía Latinoamericana Contemporánea, México, Editor Consejo Mexicano de la Fotografía, 1978, p.20.Durante la exposición que acompaña el primer coloquio domina una fotografía documental, que se quiere comprometida políticamente y representa lo que será identificado a partir de los años 1990 como estereotipos sobre América latina : la violencia y la pobreza, la contestación social y la lucha armada, la revolución cubana, las comunidades indígenas, entre otros. Un vistazo a la exposición organizada en 1982 en Centro Pompidou de Paris y titulada La photographie contemporaine en Amérique latine revela con evidencia que esas categorías están entendidas como características de la fotografía latinoamericana. Esas representaciones están aun alimentadas hoy en día por ciertas instituciones, pensamos por ejemplo a las fotografías premiadas en 2012 por el Centro Latinoamericano de Fotografía que presida el fotógrafo suizo René Burri.Cf. https:// www.facebook.com/media/set/?set=a.496317007056336.109367.464967550191282\&type=1

5. "después de que lo latinoamericano haya reclamado tan insistemente su derecho al contexto, es decir, después de que lo latinoamericano haya usado su "regionalismo critico" en contra de lo universal para desafiar el idealismo transcendental del valor estético [...] lo latinoamericano, en la escena internacional, quede restringido al "contexto" y no al "arte" : a la "diversidad cultural" y no a las problemáticas formales y discursivas del lenguaje estético".

Nelly Richard, Fragmentos de la memoria, «El régimen crítico-estético del arte en tiempos de globalización cultural », Buenos Aires, Siglo XXI, 2007, p. 82.

6. "El fotografo latinoamericano no experimenta, sino que ve [p.13]. La fotografia experimental es un propósito recurrente en la historia de la fotografía europea y norteamericana. En los países latinoamericanos su presencia es irrelevante [...] la fotografia de América Latina constituye una iconografia sobre personas y espacios vitales. Esta totalmente orientada a la realidad de la existencia y desconectada por completo de cualquier veleidad que tienda a la experimentacion artistica".

Erika Billeter, Canto a la realidad: Fotografia latinoamericana 1860 - 1993, Barcelona, Edición Lunwerg, 1993, p. 13. y p. 30.

7. Es importante matizar esa idea de ruptura ya que ciertas exposiciones contemporáneas retoman ciertos predicados que contribuyeron a caracterizar la fotografía latinoamericana. La exposición América Latina 1960 - 2013 (Fundación Cartier y museo Amparo de Puebla) hizo del político el denominador común de la fotografía latinoamericana y así reanudó con la caracterización propuesta por el Coloquio de 1978, quien forjó la expresión desde entonces obsoleta de "fotografía de la liberación". La expresión no es retomada en la exposición América Latina aunque estima que el contexto político latinoamericano federó los artistas alrededor de un compromiso ético desde los años 1960. La historia de la fotografía latinoamericana que propone la exposición reposa sin embargo sobre un nuevo predicado: en los contextos políticos de regímenes autoritarios, las artistas no hubieran tenido otros recursos que experimentar artísticamente para difundir, a pesar de la censura, un discurso critico. Ese nuevo predicado permite descartar la idea que las producciones fotográficas latinoamericanas se caracterizan por un acercamiento esencialmente documental y permite inscribir la fotografía latinoamericana en 
el relato canónico y las categorías de la historia del arte y de la fotografía (arte conceptual, performance, estilo documental, etc.).

8. Esta imposibilidad de definir la fotografía latinoamericana está a menudo formulada a partir de una incapacidad estructural, pero recientemente reconocida, a definir la identidad latinoamericana. Esta imposibilidad está implicada por el fracaso y el abandono en las ciencias humanas de las concepciones esencialistas de las identidades, en beneficio de concepciones plurales y dinámicas. En la tesis de doctorado que estoy llevando, analizo la manera con la cual la fotografía ha proveído representaciones alimentando cada una de esas dos concepciones de la identidad.

9. « No existe UNA fotografía latinoamericana, porque hay influencias de todos lados. Pero hay realidades que son latinoamericanas y que no se dan en otros sitios. $\mathrm{Y}$ eso, yo creo que si, sin duda produce una forma de ver los temas y una forma de enfrentarse a esa realidad muy particular ». Claudi Carreras, http://revistanuestramirada.org/suenodelarazon/claudi-carreras entrevista realizada por Luis Weinstein, publicada el 19 de octubre del 2009. Sitio internet consultado el 22 de octubre del 2013.

10. Para dar algunos ejemplos y subrayando las palabras que pertenecen al mismo vocabulario:

América latina, 1960 - 2013, Fondation Cartier/Museo Amparo de Puebla, 2013 : "Territorios", "Ciudades", "Informar Denunciar", "Memoria e identidad", "Revuelta(s)" ;

Urbes Mutantes, México, RM, 2013 : [...], "Los olvidados", [...], “Identidades";

11. "la escena de la fotografía latinoamericana de esos últimos años ve jugarse una vasta cosmogonía de reflexiones sobre la identidad y la memoria".

declara por ejemplo Alejandro Castellote, Photoquai, Musée du Quai Branly, Paris, edición Nicolas Chaudun, 2007, p. 24.

Nuestra traducción de : "la scène de la photographie latino-américaine de ces dernières années voit se jouer une vaste cosmogonie de réflexions sur l'identité et la mémoire".

12. Juan Antonio Molina, «La historia a contrapelo », Modelos visuales y teóricos para el análisis de la fotografía contemporánea en América Latina. Situaciones artísticas Latinoamericanas. San José de Costa Rica. TEOR/éTICA/The Getty Foundation, 2005.

13. Nuestra traducción de : "Au cours des années 1990, les photographes tentent de se défaire de l'image rurale, violente et tiers-mondiste commune dans les représentations de la décennie antérieure, c'est-à-dire de dépasser le culte du réalisme magique et de l'indigénisme ".

Alejandro Castellote, Photoquai, op.cit., p. 22.

14. La memoria en adelante hace parte de las herramientas y de los intereses de los historiadores, sin embargo memoria e historia no sabrían ser amalgamados : "lo importante primero es el entre : ubicarse entre historia y memoria, no oponerlos, ni confundirlos tampoco, pero servirse de una y de la otra. Apoyarse de la memoria para renovar y alargar el campo de la historia contemporánea".

Nuestra traducción de: "l'important est d'abord le entre: se positionner entre histoire et mémoire, ne pas les opposer, ni les confondre non plus, mais se servir de l'une et de l'autre. Faire appel à la mémoire pour renouveler et élargir le champ de l'histoire contemporaine“.

François Hartog, Régimes d'historicité. Présentisme et expériences du temps, Paris, Seuil, 2002, p. 169.

En español : Regímenes de historicidad. Presentismo y experiencias del tiempo, Mexico, Universidad Iberoamericana, 2007.

15. Nuestra traducción de : "en fonction du présent, des relectures constantes du passé qui doit pouvoir être constamment remis en cause "

Jacques Le Goff, Histoire et mémoire, Paris, Gallimard, 1988, p. 56.

16. Al respecto, ver las obras de Maurice Halbwachs :

17. En ciertos trabajos fotográficos, en particular los que tratan o tocan el tema de la globalización cultural y de la modernidad, ese heterogeneidad es también espacial o contextual, evidenciando lo que Néstor García Canclini describe cuando forja su concepto de hibridación 
cultural : "Hoy concebimos a América Latina como una articulación mas compleja de tradiciones y modernidades (diversas, desiguales), un continente heterogéneo formado por países donde, en cada uno, coexisten múltiples lógicas de desarrollo".

Néstor García Canclini, Culturas Hibridas. Estrategias para entrar y salir de la modernidad, Buenos Aires, Paidós, 2005, p. 26.

18. En la tesis de doctorado en la cual planteamos el estudio de esas relaciones como método de acercamiento a las problemáticas vinculadas en la fotografía latinoamericana con los términos historia, memoria e identidad, distinguimos otras relaciones al pasado. Para presentar a modo de resumen esas relaciones: 1. Reapropiarse el pasado. 2. Deconstruir el pasado. 3. Contemporaneidad del pasado con la memoria de los desaparecidos, con las teorías decoloniales y con el ritual como forma utópica de resurgimiento del pasado.

Tesis de doctorado: Las relaciones al pasado (historia y memorias) en la fotografía contemporánea latinoamericana. Modalidades éticas y estéticas, Mathieu Corp, Universidad Paris 3-Sorbonne Nouvelle, defensa programada en marzo del 2015.

19. Sobre las fotografías digitales a partir de las cuales los retratos han sido realizados e imprimidos sobre lino, la artista incrustó distintos materiales que han sido tejidos o pegados : a veces plástico, pero sobre todo tela, madera, arcilla, cuero, hilos de oro o de plata, yute, plumas, joyas, jade y obsidiana en particular, que coleccionó en diferentes países de América latina, así como lo hizo con las historias a las que remiten los nombres que la artista puso a cada retratada.

20. El caso de la "Chingada" por México (llamada muy a menudo la "Malinche" o "Doña Marina" que es el nombre que le dieron los conquistadores) es un famoso ejemplo. La figura de esa indígena dada como esclava a Hernán Cortés, que fue también su intérprete y amante, cristaliza las contradicciones con las cuales se creó el relato mítico del nacimiento de la nación mexicana.

21. La obra de Bartolomé de las Casas fue publicada por primera vez en 1552 bajo el titulo, Brevisima relación de la destrucción de las Indias. La artista utiliza aquí la portada de la traducción francesa del libro que fue publicado en 1579 bajo el titulo Tyrannies et cruautés des Espagnols perpétrées ès Indes occidentales, qu'on dit le Nouveau Monde.

22. Cf. Georges Didi-Huberman, La imagen superviviente. Historia del arte y tiempo de los fantasmas según Aby Warburg, Barcelona, Abada, 2009.

23. Pensamos por ejemplo a los trabajos de Marcel Gautherot, Lucien Hervé, René Burri y Julius Shulman.

24. Nuestra traducción de : "O objetivo deste trabalho é a reconstrução da memória deste fato histórico que foi ocultado na história oficial de Brasília”.

Nair Heloisa Bicalho de Sousa, «O massacre de Pacheco Fernandes Dantas em 1959 : memória dos trabalhadores da construção civil de Brasília », 2011.

http://www.derhuman.jus.gov.ar/conti/2011/10/mesa_11/bicalho_mesa_11.pdf, pagina web consultada el 20 de mayo del 2013.

25. Nuestra traducción de : "exigence de lutte contre l'oubli que l'histoire ne saurait satisfaire". 26. Nuestra traducción de : "violence à la réalité individuelle du passé [...] fiction mythique".

Friedrich Nietzsche, Considérations inactuelles (Unzeitgemässe Betrachtungen), Paris, AubierMontaigne, 1964, p. 229.

27. Márcio de Oliveira, Brasília : o mito na trajetória da Nação, São Paulo, Paralelo 15, 2005.

28. Además es amplitud va mas allá de la escala geográfica ya que se considera como latinoamericanos a artistas (peruanos, mexicanos, brasileños, etc.) que radican fuera de América latina y que han recibido una formación artística en Europa o Estados Unidos. Al parecer mas que una pertenencia geográfica, es la temática de trabajo y la posición de enunciación que determina si un trabajo fotográfico es latinoamericano o no. 


\section{RESÚMENES}

El acercamiento a la fotografía latinoamericana ha sido mucho tiempo dominado por la cuestión del valor critico y contextual de las obras, al detrimento de una atención a sus cualidades artísticas. Desde los años noventa, curadores y críticos quisieron romper con este acercamiento para celebrar la heterogeneidad y las cualidades formales de las practicas fotográficas. Para seguir legitimando la escala "América latina" de las muestras, reúnen obras distintas bajo ciertas categorías temáticas que vuelven de manera recurrente y que identifican los términos: historia, memoria e identidad. En la tesis de la cual brotan las reflexiones que componen ese articulo, propongo un análisis de las problemáticas y de las relaciones al pasado cuyos términos constituyen un indicio, a partir de un acercamiento a las imágenes articulando el valor critico y contextual de las obras a sus cualidades artísticas.

L'approche de la " photographie latino-américaine » a longtemps été dominée par la question de la valeur critique et contextuelle des œuvres, au détriment d'une mise en évidence de leurs qualités artistiques. Depuis les années 1990, commissaires et critiques ont voulu rompre avec cette approche pour célébrer l'hétérogénéité et les qualités formelles des pratiques photographiques. Pour continuer de légitimer l'échelle «Amérique latine » des expositions, ils ont réuni des œuvres différentes dans certaines catégories thématiques qui reviennent de manière récurrente et qu'identifient les termes : histoire, mémoire et identité. Dans la thèse d'où sont issues les réflexions qui composent cet article, je propose une analyse des problématiques et des rapports au passé dont ces termes sont l'indice, à partir d'une approche des images articulant la valeur critique et contextuelle des œuvres à leurs qualités artistiques.

\section{ÍNDICE}

Palabras claves: fotografía latinoamericana, historia, memoria, identidad, curaduría Mots-clés: photographie latino-américaine, histoire, mémoire, identité, commissaires d'exposition

\section{AUTOR}

MATHIEU CORP

EHESS-CERMA 